\title{
Incandescent lighting and powder metallurgical manufacturing of tungsten wire
}

\author{
Hans-Joachim Lunk
}

Received: 7 November 2014/ Accepted: 11 November 2014/Published online: 2 December 2014

(C) Springer International Publishing 2014

\begin{abstract}
This paper presents a historic overview, starting with a fireplace as source for illumination via the carbon filament lamp and ending with the IR-coated halogen lamp. The physico-chemical principles of the different periods of incandescent lighting are "illuminated." The chemical and technological basics of powder metallurgical manufacturing of tungsten wire as well as the significance of this revolutionary technology for the mass production of incandescent lamps are demonstrated. In conclusion, a comparison of the modern incandescent lamp with alternative light sources is given.
\end{abstract}

Keywords Historic overview · Incandescent lighting · Powder metallurgy · Tungsten wire

\section{Illumination prior to the incandescent lamp}

Johann Wolfgang von Goethe's legendary last words "More light" were later also philosophically interpreted. But maybe he simply ordered his servant Friedrich Krause to open the shutters. It could also be just a Frankfurt's jargon like "Mer liecht (I lie = 'more light') here so uncomfortable" or even just the call after the Botschanper (a malapropism of "pot de chambre"-pisspot). Unfortunately, it cannot be clarified anymore. But since the beginning of time the human race cannot do without artificial lighting. Table 1 shows a condensed time travel prior to the incandescent lamp.

Electronic supplementary material The online version of this article (doi:10.1007/s40828-014-0003-8) contains supplementary material, which is available to authorized users.

H.-J. Lunk ( $₫)$

Global Tungsten \& Powders Corp. (GTP), 2858 Lake Road,

Towanda, PA 18848, USA

e-mail: baaclunk@epix.net

\section{Basic knowledge for generating light by an incandescent body}

The wavelength distribution of light generated by an incandescent body is described by Planck's radiation law. Like the Sun's spectrum, it is continuous. Compared to the Sun's temperature, however, the temperature of an incandescent body is very low. Therefore, the light's red portion predominates, while blue is only poorly represented. With increasing temperature, the radiation maximum shifts in accordance with Wien's displacement law $\lambda_{\max }=2.8978 \times 10^{6} \mathrm{~nm} \mathrm{~K} \mathrm{~T}^{-1} \quad\left(\lambda_{\max }:\right.$ wavelength maximum; $T$ : absolute temperature of the radiation surface) to smaller wavelengths and thereby to the visible region (400-800 $\mathrm{nm}$ ), but always remains in the IR region.

The Stefan-Boltzmann law specifies which radiant flux $P$ a Black body of the area $A$ and the absolute temperature $T$ emits. Using the Stefan-Boltzmann constant $\sigma$, it corresponds to $P=\sigma A T^{4}$. Accordingly, a Black-body's radiation is proportional to the fourth power of its absolute temperature. So, doubling the temperature causes an increase of the radiation by a factor of 16 . This law is also called Boltzmann's T-to-the-fourth law. For getting a high light output, the radiation maximum must be shifted by temperature increase from the long-wave infrared heat radiation as far as possible to the range of visible light, without getting too close to the melting temperature of the material used. Almost the entire input power is converted into radiation. The losses by conduction and convection are minimal. However, only the wavelength range of radiation $400-800 \mathrm{~nm}$ is visible to the human eye. The main portion is located in the invisible infrared region and cannot be used for lighting purposes. 


\section{Brief history of the light bulb}

When people are asked, who invented the incandescent lamp (vernacular "incandescent pear"), most of them would mention the name of Thomas Alva Edison. However, the corresponding "incandescent story" started a lot

Table 1 Light sources prior to the incandescent lamp

\begin{tabular}{ll}
\hline $\begin{array}{l}\text { About 250,000 } \\
\text { B.C.E. }\end{array}$ & Open fireplaces \\
8,000 B.C.E. & Bowl lamp (precursor of clay lamp) \\
700 B.C.E. & Clay lamp \\
2nd Century AD & Appearance of candles in the Roman Empire \\
1783 & Argand's oil lamp (François Pierre Ami Argand) \\
$1798 / 1802$ & Gas light in English factories \\
1799 & Gas light patent of Philippe Lebon in Paris \\
1800 & Discovery of electric arc between carbon \\
& electrodes \\
1830 & Paraffin candle \\
1857 & Heinrich Geißler invented the discharge tube \\
1862 & Justus Liebig discovered acetylene gas for the \\
& carbide lamp
\end{tabular}

Table 2 The journey from platinum filament to tungsten coil

\begin{tabular}{|c|c|c|c|}
\hline Year & Inventor (Country) & $\begin{array}{l}\text { Material of the light } \\
\text { source }\end{array}$ & Atmosphere \\
\hline 1801 & $\begin{array}{l}\text { Louis Jacques } \\
\text { Thénard (FR) }\end{array}$ & $\begin{array}{l}\text { Metal wires brought } \\
\text { to a bright glow }\end{array}$ & Air \\
\hline 1809 & $\begin{array}{l}\text { Warren De la Rue } \\
\text { (GB) }\end{array}$ & Platinum filament & Vacuum \\
\hline 1838 & $\begin{array}{l}\text { Jean Baptiste } \\
\text { Ambroise Marcellin } \\
\text { Jobard (BE) }\end{array}$ & Carbon rod & Vacuum \\
\hline 1845 & $\begin{array}{l}\text { John Wellington Starr } \\
\text { (US) }\end{array}$ & Graphite rod & Vacuum \\
\hline 1849 & William Petrie (GB) & $\begin{array}{l}\text { Iridium and Iridium } \\
\text { alloys }\end{array}$ & Air \\
\hline 1850 & $\begin{array}{l}\text { Edward C. Shepard } \\
\text { (US) }\end{array}$ & Charcoal cylinder & Vacuum \\
\hline 1854 & Heinrich Goebel (DE) & Carbon filament & Vacuum \\
\hline 1860 & $\begin{array}{l}\text { Joseph Wilson Swan } \\
\text { (GB) }\end{array}$ & Carbon rod & Vacuum \\
\hline 1881 & $\begin{array}{l}\text { Thomas Alva Edison } \\
\text { (US) }\end{array}$ & Carbon filament & Vacuum \\
\hline 1889 & $\begin{array}{l}\text { Carl Auer von } \\
\text { Welsbach (AT) }\end{array}$ & Osmium wire & Vacuum \\
\hline 1897 & $\begin{array}{l}\text { Walther Herman } \\
\text { Nernst (DE) }\end{array}$ & $\begin{array}{l}\text { Nernst lamp: } \\
\text { ceramics made from } \\
\mathrm{ZrO}_{2}-\mathrm{Y}_{2} \mathrm{O}_{3}\end{array}$ & Air \\
\hline 1903 & $\begin{array}{l}\text { Werner Bolton und } \\
\text { Otto Feuerlein (DE) }\end{array}$ & Tantalum wire & Vacuum \\
\hline 1911 & $\begin{array}{l}\text { William David } \\
\text { Coolidge (US) }\end{array}$ & Tungsten wire & Vacuum \\
\hline
\end{tabular}

earlier. Table 2 summarizes the most important steps of lighting using a material, which is heated up by electric power to glow. These so-called thermal radiators generate light by electric power, which flows through a suitable material. Unfortunately, only a low percentage of the applied energy is converted to visible light. Not all inventors, who have provided valuable contributions over a period of 110 years to the development of an incandescent tungsten filament, could be listed here.

History and present of the incandescent lamp can be found in the following overviews.

http://www.debook.com/Bulbs/LB00intro.htm,

http://www.streetlight-hamburg.de/index.htm,

http://www.rbs0.com/wlamp.pdf,

http://www.halogen-control.de/html/produkte/Wissens

wertes_Halogenlampen.pdf,

http://www.globaltungsten.com,

http://www.osram.de,

Interesting is also a presentation on YouTube:

http://www.edisontechcenter.org/incandescent.html

\section{Carbon filament light bulb: Joseph Wilson Swan versus Thomas Alva Edison}

Beginning with the 1850 s, patents for light bulbs were filed in quite large numbers. However, the developers failed to produce longer-lasting bulbs due to the then-imperfect vacuum technology. After the invention and distribution of the vacuum pump, the design efforts were intensified. As a result, in the 1870s numerous patent applications were filed in different countries. The function of these lamps was still limited to less than $10 \mathrm{~h}$. In addition to the shelf life of the lamps, the economic energy consumption was a huge problem.

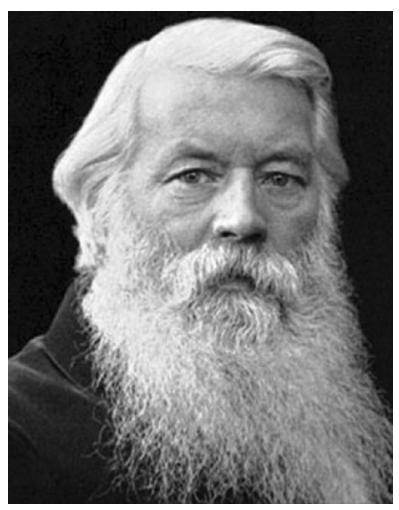

Joseph Wilson Swan (1828-1914)

Let us now focus on the Briton Swan and the American Edison, the main players in the competition for the best carbon filament incandescent lamp. In 1850, the physicist 
and chemist Joseph Wilson Swan began his studies on the generation of electric light. His first models contained a carbonized paper thread in an evacuated glass bulb. The corresponding British patent was granted to him in 1860 . This lamp, however, was unfit for a general use due to the poor vacuum and problems with the electrical supply. In 1878, Swan patented an improved lamp version with a carbonized thread. As a result of the better vacuum, the oxygen content was low. Due to the low resistance of the carbon threads, Swan had to use thick copper wires for the electrical supply. Nonetheless, Swan's house in Gateshead was the first house worldwide, equipped with functioning bulbs. In 1880, he started The Swan Electric Light Company, which produced commercial light bulbs.

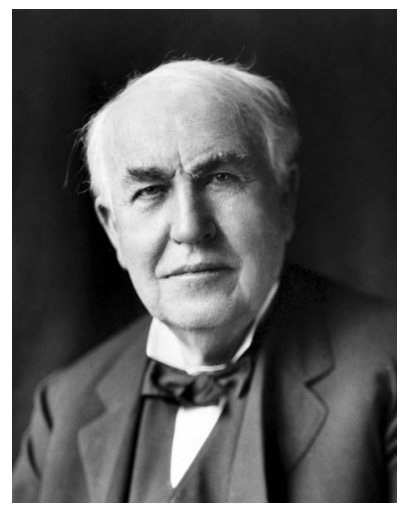

Thomas Alva Edison(1847-1931)

Meanwhile, Thomas Alva Edison in the United States worked on his version of an incandescent lamp. His works based essentially on a patent acquired in 1875 from Henry Woodward and Matthew Evans, as well as on the two patents of Swan. Edison improved the light bulb and received the basic patent 223,898 US for its developments in the United States on January 27, 1880. As a side note, the invention date November 4, 1879, mentioned in numerous publications, is merely the patent's earlier filing date. Edison's light bulb consisted of an evacuated glass bulb with a carbon filament of carbonized bamboo fibers. The American patent granted to Edison was a direct copy of Swan's lamp. Swan consequently defeated Edison in the trial for patent infringement. However, he provided Edison the right to produce light bulbs in the United States, while he kept his rights in England. Edison was also required to take Swan as a partner in his British electricity-generating plants. In 1883, the Edison \& Swan United electric light company (Ediswan) was founded. Ediswan marketed incandescent lamps, which contained a better filament, patented by Swan in 1881. This new industry standard used an alcohol/ether solution of nitrocellulose, which was sprayed into a precipitation bath. Subsequently, the formed threads were carburized. The Edison General Electric Company continued to use the carbonized bamboo thread developed by Edison. Numerous improvements particularly in the precise filament manufacture led to light bulbs, wherewith Edison successfully competed with the common gas lamps. Durability, light output, and energy costs played a major role. In contrast to Swan's lamps, Edison's incandescent lamps were equipped with high-resistance filaments. The fabrication of these lamps was certainly difficult, but a power grid considerably simplified their usage and reduced the overall costs significantly. Using high voltage for high-resistance appliances, the electricity could be more easily transported. In addition, significant amounts of copper were saved as a lower wire cross section could be used. Now the energy supply for electricity was technically feasible and competitive with the existing grid for gas lamps. In particular, Edison could resolve the problem of the divisibility of light with his high-impedance lamps. All previous solutions had required an individual power source for few lamps. Edison's incandescent lamp was the first ever that was fabricated not only in small numbers, but also went into serial production. Therefore, we rightfully should credit Thomas Alva Edison with the invention of a practically usable light bulb. In 1892, The Edison General Electric Company emerged with the Thomson-Houston Electric Company to General Electric $(G E)$. From now on, GE also used the cellulose-based carbon filament developed by Swan.

Although carbon has a higher melting point $\left(3,547^{\circ} \mathrm{C}\right)$ than tungsten $\left(3,420^{\circ} \mathrm{C}\right)$, its vapor pressure reaches the high value of $1 \mathrm{~Pa}\left(7.5 \times 10^{-3}\right.$ Torr $)$ already at $2,437{ }^{\circ} \mathrm{C}$. This leads to the early blackening of the glass flask at relatively low temperatures of the carbon thread. The already low light output (see "Basic knowledge for generating light by an incandescent body" and "Light parameters") as a result of the limited operating temperature drops still further.

The use of carbon filament light bulbs in households in the 1880s went hand in hand with the development of distribution grids for electric energy. This marked the beginning of the ubiquitous electrification. In Germany, the Café Bauer Unter den Linden in Berlin was the first building, which in 1884 was illuminated with incandescent lamps. The light bulbs were produced by Emil Moritz Rathenau (father of Walther Rathenau, the Foreign Minister during the Weimar Republic) based on Edison's patents. In 1883, Rathenau founded the German Edison Society for Applied Electricity, which in 1887 was converted into the General Electricity Association (AEG). In the same year, Rathenau and his rival and at the same time business partner Werner von Siemens founded the Telefunken Society for Wireless Telegraphy $m b H$. 


\section{From osmium to tantalum lamp}

The fundamental suitability of osmium (m.p. $3,045^{\circ} \mathrm{C}$ ), tantalum (m.p. $2,996{ }^{\circ} \mathrm{C}$ ), and tungsten (m.p. $3,420{ }^{\circ} \mathrm{C}$ ) for filaments was obvious, due to the high melting points of these metals. But only technical developments in powder metallurgy allowed the economic processibility of these rare and at the same time expensive materials. The processing problems were particularly immense in the case of the extremely hard and brittle tungsten. The Austrian chemist and founder of OSRAM (OSmium/wolfRAM, 'Wolfram' is the German word for 'tungsten') Carl Auer von Welsbach made an important contribution to the invention of a light bulb equipped with a metallic filament. In 1898, his German 'Reichspatent' 38,135 was filed: "Manufacturing of osmium filaments and their use for electrical incandescent lamps." Auer von Welsbach is also the discoverer of the four rare-earth metals praseodymium (element 59), neodymium (60), ytterbium (70), and lutetium (71) as well as of the incandescent gas mantle ("Auer sock") and the flint ("Auer metal") of the lighter.

Incandescent lamps with drawn tantalum wires were developed in 1902 by Werner von Bolton [1]. These lamps achieved a luminous efficacy (see Table 4) comparable with the osmium lamp, however, with lower energy consumption. Until 1905, headed by Werner von Bolton and Otto Feuerlein, the tantalum lamps were produced at Siemens \& Halske $A G$ and shipped to customers in large quantities. The tantalum wire replaced the osmium wire lamps and subsequently gradually the carbon filament lamps. The tantalum lamp was, however, only a short episode in the history of the light bulb in the run-up to the developments of the tungsten filament lamp. Remarkably, until the outbreak of WWI, over 50 million tantalum lamps were manufactured and sold. So, the "unsinkable" luxury liner Titanic was completely equipped with tantalum wire lamps. On its maiden voyage, it rammed an iceberg on April 14, 1912, and approximately 1,500 people were ripped to their deaths.

\section{From the carbon filament lamp to the modern light bulb}

Tungsten is one of the high-melting metals, also called refractory metals. All metals with a higher melting point than platinum $\left(1,772{ }^{\circ} \mathrm{C}\right)$ belong to this privileged group. Very soon it became obvious that tungsten should be the ideal material for light bulbs. It has the highest melting point of all metals $\left(3,420{ }^{\circ} \mathrm{C}\right)$, and its evaporation rate is very low up to high temperatures. For instance, its vapor pressure at $1,800{ }^{\circ} \mathrm{C}$ amounts to $2 \times 10^{-9} \mathrm{~Pa}$, at $2,200{ }^{\circ} \mathrm{C}$ to $6 \times 0^{-6} \mathrm{~Pa}$ and reached even at $3,003{ }^{\circ} \mathrm{C}$ only $0.133 \mathrm{~Pa}$ $\left(10^{-3}\right.$ Torr $)$. As a result of its high molar mass of $183.85 \mathrm{~g} \mathrm{~mol}^{-1}$, tungsten has a low specific heat capacity of $c_{\mathrm{sp}}(293 \mathrm{~K})=0.0321 \mathrm{cal} \mathrm{K}^{-1} \mathrm{~g}^{-1}\left(0.1344 \mathrm{~J} \mathrm{~K}^{-1} \mathrm{~g}^{-1}\right)$. Tungsten also has the lowest linear expansion coefficient of all metals: $4.6 \times 10^{-6} \mathrm{~K}^{-1}$ at $27^{\circ} \mathrm{C}$ and $7.3 \times 10^{-6} \mathrm{~K}^{-1}$ at $2,100{ }^{\circ} \mathrm{C}$.

At $20^{\circ} \mathrm{C}$, the elasticity modulus for the tungsten single crystal amounts to $35,000-40,000 \mathrm{~kg} \mathrm{~mm}^{-2}$. The hightemperature tensile strength combined with the high E-modulus enables tungsten's high creep resistance. Tungsten has a body-centered cubic lattice, and hence the same characteristic brittle-ductile transition as molybdenum. The corresponding transition temperature can be shifted by deformation and alloying to lower temperatures. The strength rises with increasing degree of deformation. In contrast to other metals, the ductility of tungsten also upturns in this direction. All in all, tungsten possesses ideal characteristics to be used as filament. There was "only" one problem. How would it be able to produce a ductile tungsten wire? The "magic" technology was and is the powder metallurgy. The details of the powder metallurgical manufacture are presented in several monographs [2-7]. There exist six crucial development steps on the way from the carbon filament to the modern tungsten coil lamp.

- Replacement of carbon thread by tungsten wire (1909)

- Filling the bulb with an inert gas (1914)

- "Coiling" the filament to a single-coil (1913) and a coiled-coil filament (1926)

- "Doping" of tungsten trioxide with potassium-, siliconand aluminum-containing compounds (1922)

- Addition of halogens to the filling gas (1959)

- Infrared coating of the bulb (1996)

Replacement of carbon thread by tungsten wire

\section{Powder metallurgical production of tungsten wire}

In 1909, William David Coolidge and his team at GE achieved the decisive breakthrough with the powder metallurgy production of tungsten wire (British patent 23,499). Coolidge successfully adapted the 80-year-old powder metallurgical method for making platinum parts (developed by Petr Grigorevich Sobolevsky $[8,9])$ to the production of ductile tungsten.

Examples of the four generations of incandescent lamps from Edison to Coolidge are shown in Fig. 1.

Numerous industrial metals and alloys such as aluminum, copper, and many steel varieties are produced by melting processes. What is so fascinating about powder metallurgy? Remarkably, in this case the melting point is never reached; it is simply bypassed. Using this technology, composite materials are possible for different 


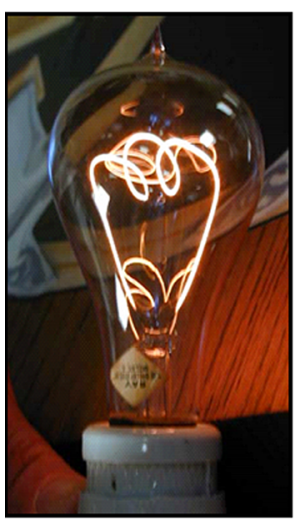

(a)

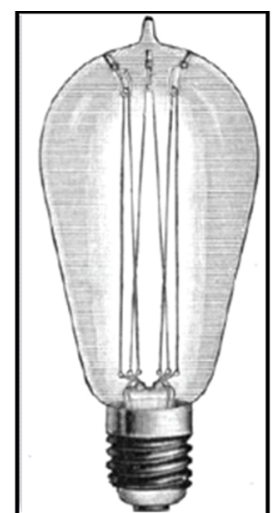

(b)

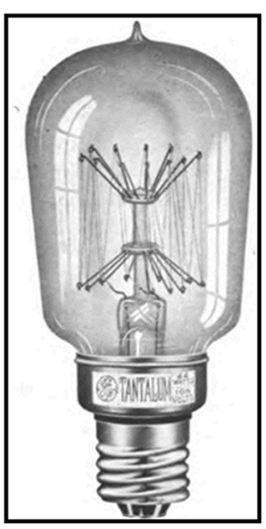

(c)

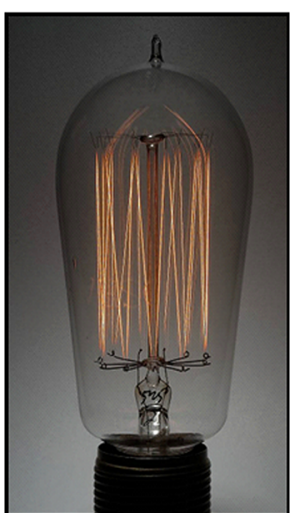

(d)

Fig. 1 Four generations of incandescent lamps. a Legendary "century" carbon filament lamp (Fire Department, Livermore, CA, United States). b Osmium lamp. c Tantalum lamp. d One of the first Coolidge lamps with drawn tungsten wire (1911)

components, which are not producible using melting metallurgy. The end products are fabricated by pressing the corresponding metal powders and subsequent heat treatment far below the melting temperature of the material. The so-called sintering presents the central technological step of powder metallurgy. Metals with melting points far above $2,000{ }^{\circ} \mathrm{C}$ are produced by this revolutionary technology. It can also be used for fabrication of homogeneous materials with selected properties from tailored powder mixtures, e.g., the polycrystalline tungsten carbides. Generally, a powder metallurgy process even at small production quantities is still very economical.

\section{Tungsten powder production}

In the early years of the powder metallurgy production of tungsten wire exclusively the yellow tungsten trioxide, $\mathrm{WO}_{3}$, served as starting compound (Fig. 2). It was produced either by calcination in air of "tungstic acid," $\mathrm{WO}_{3}$ $\mathrm{H}_{2} \mathrm{O}$, (correct nomenclature: tungsten trioxide monohydrate), or of ammonium paratungstate tetrahydrate (APT), $\left(\mathrm{NH}_{4}\right)_{10}\left[\mathrm{H}_{2} \mathrm{~W}_{12} \mathrm{O}_{42}\right] 4 \mathrm{H}_{2} \mathrm{O}$ (Fig. 3). APT is a prominent representative of the isopolyoxometalates [10]. The scanning electron micrograph of a tungsten powder with the average grain size of $4 \mu \mathrm{m}$ is shown in Fig. 4 .

Nowadays, all over the world-and not only for the production of tungsten wire- "tungsten blue oxide" (TBO) is utilized as starting material. However, the frequently used term TBO does not represent a well-defined chemical compound, but is only the designation of a bluecolored industrially manufactured oxidic tungsten compound. TBO is produced favorably in rotary kilns by partial thermal decomposition of APT in reducing atmospheres, mostly in hydrogen. Its overall composition $x \mathrm{NH}_{3} \cdot y \mathrm{H}_{2} \mathrm{O} \cdot \mathrm{WO}_{n}$ $(n<3)$ is determined by the chosen production conditions such as heating rate, maximum temperature, atmosphere, gas flow, and APT throughput. Using quantitative chemical analysis, qualitative and quantitative $\mathrm{X}$-ray techniques, as well as high-resolution ${ }^{1} \mathrm{H}-\mathrm{NMR}$ spectroscopy, it was shown that TBO's composition of leading manufacturers is quite different. In addition to the crystalline compounds $\mathrm{WO}_{3}$ (Fig. 2), hexagonal tungsten bronze, $\left(\mathrm{NH}_{4}\right)_{\mathrm{n}} \mathrm{WO}_{3} \quad(0<n \leq 0.33)$, (Fig. 5) as well as the "tungsten suboxides" $\mathrm{W}_{20} \mathrm{O}_{58} \quad\left(\mathrm{WO}_{2.90}\right)$ and $\mathrm{W}_{18} \mathrm{O}_{49}$ $\left(\mathrm{WO}_{2.72}\right)$, most TBOs also contain X-ray amorphous components. These phases are represented in different TBOs in variable proportions [11]. If the thermal decomposition of APT is carried out in the temperature range of $500-600{ }^{\circ} \mathrm{C}$, the produced TBO contains significant amounts of $\left(\mathrm{NH}_{4}\right)_{n} \mathrm{WO}_{3}$ (see " "Doping" of $\mathrm{WO}_{3}$ and TBO"). The change in color from colorless to blue is the result of a reduction process, whereby the oxidation states $\mathrm{W}^{5+}$ and/or $\mathrm{W}^{4+}$ are produced. The cation-cation charge transfer between $\mathrm{W}^{6+}$ and a reduced tungsten species is the reason for the color change [12].

\section{Pressing and sintering}

Tungsten powder quantities up to $6 \mathrm{~kg}$ are compacted at pressures of approximately 2,000 atm to the so-called green bar. The green bar is sintered in special furnaces ("sinter bottles") in direct circuit continuity at temperatures up to $2,900{ }^{\circ} \mathrm{C}$. As the result of the sintering, the density increased from 10 to $11 \mathrm{~g} \mathrm{~cm}^{-3}$ to approx. $18 \mathrm{~g} \mathrm{~cm}^{-3}$; a specific microstructure is formed. The sintered ingot is ductile at high temperature. By its rolling, swaging, and drawing, the final tungsten wire with the theoretical density of $19.3 \mathrm{~g} \mathrm{~cm}^{-3}$ can be thinner than a human hair. Only when all steps of the metal working are perfectly synchronized, the desired high quality of the 


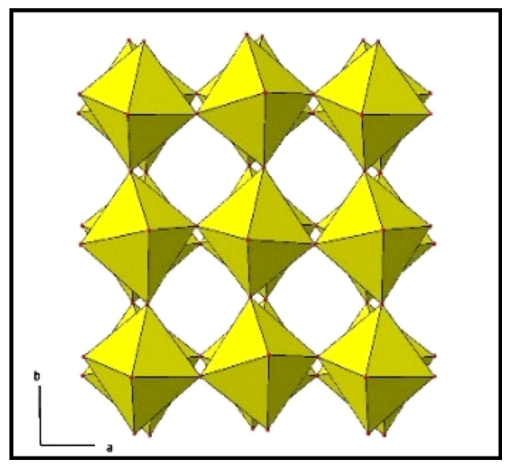

Fig. 2 Polyhedral model of $\alpha-\mathrm{WO}_{3}$

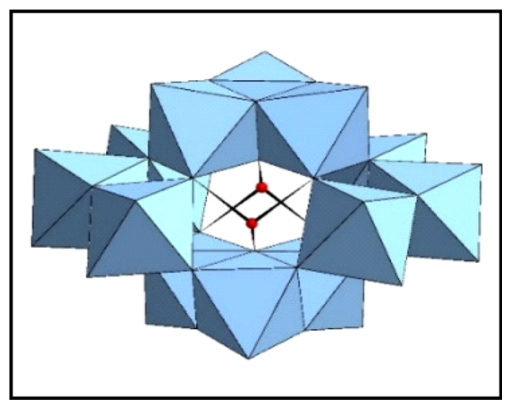

Fig. 3 Polyhedral model of $\left[\mathrm{H}_{2} \mathrm{~W}_{12} \mathrm{O}_{42}\right]^{10-}$

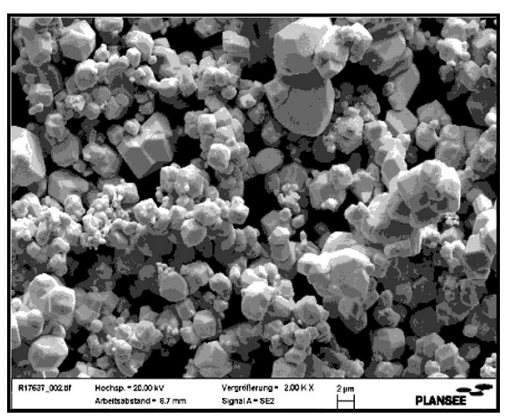

Fig. 4 SEM micrograph of tungsten powder tungsten wire as temperature strength, hardness, and flow behavior can be achieved.

Filling the bulb with an inert gas

The filling gas of the incandescent lamp transports a large part of the filament's heat away from it. Therefore, extra energy must be supplied to the filament to maintain its temperature. The heat loss depends on the type of the filling gas. It can be reduced by the "heavy" noble gases krypton (molar mass $83.798 \mathrm{~g} \mathrm{~mol}^{-1}$, density $3.749 \mathrm{~g} \mathrm{~L}^{-1}$ at $273 \mathrm{~K}$, thermal conductivity $9.43 \times 10^{-3} \mathrm{~W} \mathrm{~m}^{-1} \mathrm{~K}^{-1}$ ) or xenon (molar mass $131.29 \mathrm{~g} \mathrm{~mol}^{-1}$, density $5.989 \mathrm{~g} \mathrm{~L}^{-1}$ at $273 \mathrm{~K}$, thermal conductivity $5.65 \times 10^{-3} \mathrm{~W} \mathrm{~m}^{-1} \mathrm{~K}^{-1}$ ) instead of the noble gas argon (molar mass $39.948 \mathrm{~g} \mathrm{~mol}^{-1}$, density $1.784 \mathrm{~g} \mathrm{~L}^{-1}$ at $273 \mathrm{~K}$, thermal conductivity $17.72 \times 10^{-3} \mathrm{~W} \mathrm{~m}^{-1} \mathrm{~K}^{-1}$ ). The larger the atoms of a gas, the smaller the heat conductivity and thereby the resulting heat loss. By filling the bulb with krypton or xenon, less electric energy is required to heat up the tungsten filament. The heavy atoms also slow down the evaporation of tungsten atoms from the filament. It reduces the loss of material at the filament, and accordingly increases the lamp's lifetime.

The physicist Imre Bródy (1891-1944) was the first, who in 1930 filled lamps with krypton in lieu of argon. Production of krypton-filled lamps based on his invention started in 1937 in a factory at the Hungarian city Ajka. The invention was the most economic bulb in the age, which for decades was one of the most successful export products of Hungary.

Bródy stayed with his family after the German occupation of Hungary in 1944, and the immunity promised by the factory to him could not save his life. Being Jewish, he was murdered on December 20, 1944, at age 53, in Mühldorf subcamp, a satellite system of the Dachau concentration camp. The research institute of Tungsram, now part of General Electric, in Budapest is named after him.
Fig. 5 Hexagonal tungsten bronze structure. a Polyhedral model of hexagonal $\gamma-\mathrm{WO}_{3}$. b Ball-and-stick model (Black $\mathrm{W}$, Yellow $\mathrm{O}$, Red $\mathrm{NH}_{4}$ ) of Ammonium tungsten bronze $\left(\mathrm{NH}_{4}\right)_{n} \mathrm{WO}_{3}(0<n<0.33)$

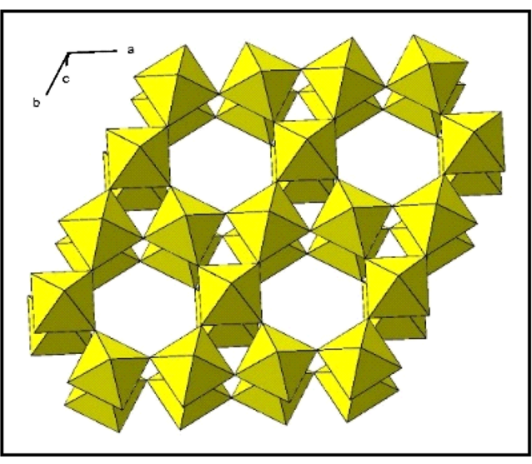

(a)

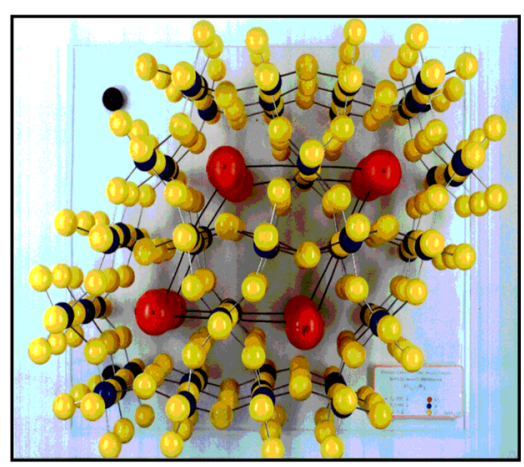

(b) 
"Coiling" the filament to a single-coil or coiled-coil filament

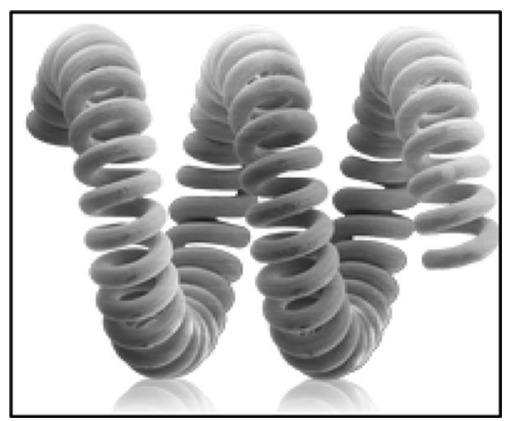

In addition to the potential increase of the temperature and thereby the light output (see "Light parameters"), metallic filaments have another advantage: They can be shaped to coils, whereby the power density is increased. The bulb is getting smaller for the same light output. In addition to the reduced space requirement, the light is better centered. The bulb is significantly smaller for the same light output. High-output lamps are often equipped with coiled-coil filaments. Besides the limited thermal convection by a small Langmuir layer, plenty of wire can be placed in a small volume. Coiled-coil filaments are fabricated by coiling tungsten wire around a molybdenum wire with a larger diameter. Afterward, the molybdenum mandrel is removed by etching with nitric acid.

\section{Addition of halogens to the filling gas}

During the extended lifetime of a light bulb, the sublimation of tungsten in the inert gas (state-of-the-art: xenon) is not preventable, despite its extremely low vapor

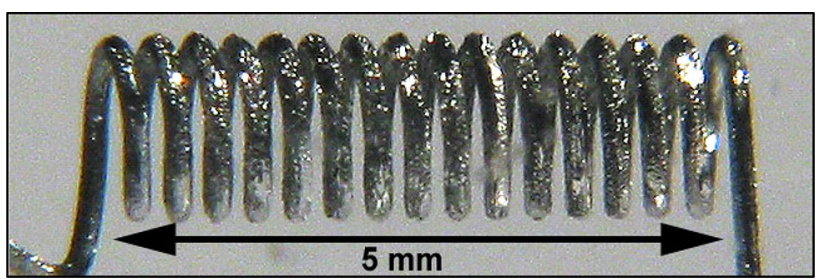

Fig. 6 Coil of a halogen lamp after several hundred hours of operating life. The crystalline deposits of tungsten can be seen

pressure. The condensation of tungsten leads to the blackening of the bulb's inside wall and thereby reduces the light output (see "Basic knowledge for generating light by an incandescent body" and "Light parameters"). The filament becomes thinner and hotter which accelerates its own destruction.

Efforts to ensure on one hand as high as possible temperatures of the glowing tungsten wire and on the other hand to reduce the evaporation rate led to the development of the tungsten halogen incandescent lamp [13]. The formation of gaseous tungsten-containing compounds prevents the blackening ("windshield wiper") of the bulb. The thermal decomposition of these compounds near the hot wire results in the deposition of tungsten on the wire (Fig. 6). The halogen (mostly bromine or iodine) is freed up and can continue the transport process. The creation of the halogen lamp constitutes an application of the van Arkel-de-Boer process (transport reaction), developed by Anton Eduard van Arkel and Jan Hendrik de Boer in 1924. This process was designed for fabrication or purification of metals such as titanium, zirconium, vanadium, chromium or rhenium, and their compounds (e.g., zirconium nitride $\mathrm{ZrN}$ ) as well as for the semi-metals boron and silicon.
Table 3 OSRAM-ECO halogen lamps

\begin{tabular}{llllllll}
\hline ECO halogen lamps & Socket & $\begin{array}{l}\text { Voltage } \\
(\mathrm{V})\end{array}$ & $\begin{array}{l}\text { Power } \\
(\text { Watt })\end{array}$ & $\begin{array}{l}\text { Luminous } \\
\text { efficacy } \\
\left(\mathrm{lm} \mathrm{W}^{-1}\right)\end{array}$ & $\begin{array}{l}\text { Color } \\
\text { temperature } \\
(\mathrm{K})\end{array}$ & $\begin{array}{l}\text { Durability } \\
(\mathrm{h})\end{array}$ & CRI \\
\hline ECO PRO CLP & E14 & 240 & 46 & 15 & 2,700 & 2,000 & 100 \\
\hline
\end{tabular}


The tungsten halogen cycle in a halogen lamp includes also the not completely excludable oxygen and can be described as follows:

$\mathrm{W}+\mathrm{O}_{2}+\mathrm{X}_{2} \rightleftharpoons \mathrm{WO}_{2} \mathrm{X}_{2}(X=\mathrm{Br}, \mathrm{I})$.

The operating temperature of a halogen lamp when compared to a traditional light bulb requires the use of tungsten wires of enhanced quality. Table 3 lists three examples of OSRAM-ECO halogen lamps.

\section{"Doping" of $\mathrm{WO}_{3}$ and $\mathrm{TBO}$}

The "doping" process, in the past of $\mathrm{WO}_{3}$, at present exclusively of TBO, is carried out with aqueous solutions of potassium silicate and aluminum nitrate or chloride. By doping the starting materials, the quality of the produced tungsten wire was improved dramatically. The total concentration of the empirically determined amounts of the "dope" elements $\mathrm{K}, \mathrm{Si}$, and $\mathrm{Al}$ amounts to about 5,000 ppm. The "dope" procedure was an accidental discovery by Aladar Pacz, back in 1922 [14]. The understanding of the role of the key element potassium was possible only since the 1960s with the help of modern analytical tools like the scanning electron microscope (SEM), the transmission electron microscope (TEM), and the Auger electron spectroscopy (AES) [1520].

Doped tungsten is a unique composite of two non-alloyable metals, which could not be more different, namely of tungsten (m.p. $3,420{ }^{\circ} \mathrm{C}$, atomic radius $137 \mathrm{pm}$ ) and potassium (m.p. $63.7^{\circ} \mathrm{C}$, atomic radius $227 \mathrm{pm}$ ). The following facts of potassium-doped tungsten have been collected over the last decades.

(A) At first an aqueous solution of potassium silicate is added to the starting materials $\mathrm{WO}_{3}$ or TBO. During this stage, depending on the composition and the pre-

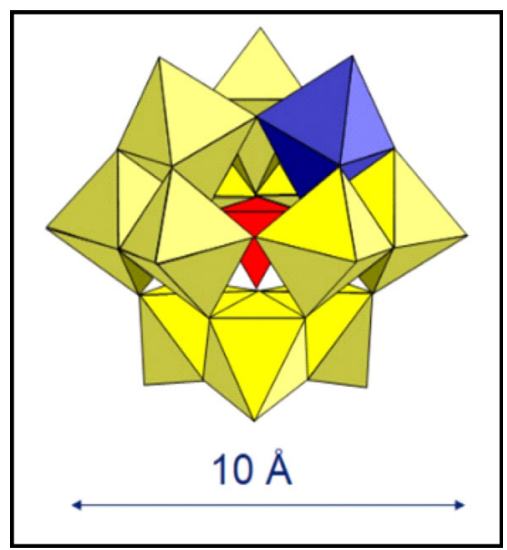

Fig. 7 Polyhedral model of the Keggin anions $\left[\alpha-\mathrm{SiO}_{4} \mathrm{~W}_{12} \mathrm{O}_{36}\right]^{4-}$ and $\left[\alpha-\mathrm{SiO}_{4} \mathrm{~W}_{11} \mathrm{O}_{35}\right]^{8-}$ treatment of the oxidic raw materials, varying amounts of the polyoxotungstates $\mathrm{K}_{4}\left[\alpha-\mathrm{SiO}_{4} \mathrm{~W}_{12} \mathrm{O}_{36}\right]$ and $\mathrm{K}_{8}\left[\alpha-\mathrm{SiO}_{4} \mathrm{~W}_{11} \mathrm{O}_{35}\right]$ are formed [10]. The polyhedral model of the famous Keggin anion is shown in Fig. 7. The anion is built by $12 \mathrm{WO}_{6}$ octahedra, which surround the central tetrahedrally coordinated "heteroatom" Si. Four edge-linked $\mathrm{W}_{3} \mathrm{O}_{13}$ groups are connected over corners. The anion $\left[\alpha-\mathrm{SiO}_{4} \mathrm{~W}_{11} \mathrm{O}_{35}\right]^{8-}$, known as "lacunar" arrangement, derives from the complete Keggin structure by removing a $\mathrm{W}=\mathrm{O}$ group (highlighted in blue).

The subsequently added aqueous solution of $\mathrm{Al}\left(\mathrm{NO}_{3}\right)_{3}$ or $\mathrm{AlCl}_{3}$ reacts with the remaining potassium silicate to insoluble potassium alumosilicates like $\mathrm{KAlSi}_{3} \mathrm{O}_{8}$ and $\mathrm{KAlSi}_{2} \mathrm{O}_{6}$ [21-23]. If the utilized TBO contains hexagonal tungsten bronze $\left(\mathrm{NH}_{4}\right)_{\mathrm{n}} \mathrm{WO}_{3}$ (see "Replacement of carbon thread by tungsten wire"), additional amounts of potassium will be incorporated into the oxidic starting material via the ion-exchange process $\mathrm{K}^{+} \rightarrow \mathrm{NH}_{4}^{+}$.

(B) The hydrogen reduction in pusher-type furnaces is usually carried out in two stages via the intermediate "brown oxide" (mixture of $\mathrm{WO}_{2}$ and $\alpha-\mathrm{W}$ ). Chemical transport reactions during the first reduction stage at temperatures around $600{ }^{\circ} \mathrm{C}$ are crucial for two reasons.

(a) To generate the precondition for an optimal grain size and grain size distribution during the second reduction stage, the tungsten powder must be moldable.

(b) To incorporate the desired amount of potassium-containing compounds into the partially reduced material.

During the second reduction stage at around $900{ }^{\circ} \mathrm{C}$, the whole $\mathrm{WO}_{3}$ or TBO is reduced to cubic bodycentered $\alpha-\mathrm{W}$. The polyoxotungstates are transformed to $\alpha-\mathrm{W}, \mathrm{K}_{2} \mathrm{WO}_{4}$, and $\mathrm{K}_{2} \mathrm{Si}_{2} \mathrm{O}_{5}$, while the potassium alumosilicates will not be reduced under these conditions. The compound $\mathrm{K}_{2} \mathrm{WO}_{4}$ is the main foreign phase in the otherwise completely reduced tungsten powder. Its amount is determined by the quantity of the formed polyoxotungstates. Their concentration in turn depends on the specific dope procedure, particularly on the composition of the dope solutions [24]. First, the water-soluble potassium monotungstate is removed by water washing the tungsten powder. Secondly, the silicate phases are decomposed by aqueous hydrofluoric acid, HF, into soluble anionic complexes such as $\left[\mathrm{SiF}_{6}\right]^{4-}$ and $\left[\mathrm{AlF}_{6}\right]^{3-}$. After thorough water wash, the powder is filtered off and dried at about $80{ }^{\circ} \mathrm{C}$. The tungsten powder has an average grain size of approx. $4 \mu \mathrm{m}$. 
Depending on the dope conditions, it contains 60-130 ppm K and insignificant amounts of remaining $\mathrm{Si}$ and $\mathrm{Al}$.

(C) During the multi-step sintering process in hydrogen, the incorporated foreign phases, which could not be removed by the washing process, are decomposed. The minute amounts of $\mathrm{Si}$ (atomic radius $117 \mathrm{pm}$ ), $\mathrm{Al}(143 \mathrm{pm})$, and $\mathrm{O}(66 \mathrm{pm})$ are initially solved in the tungsten matrix. At higher sintering temperatures, they diffuse out of the matrix. In contrast, about $70 \%$ of the potassium that had remained after up to $85 \mathrm{ppm} \mathrm{K}$. Now it exhibits the specific stable structure with elongated grains (Fig. 8), which accounts for its "non-sag" behavior. The blockage of the grain boundaries' movement perpendicular to the wire axis is the main reason for the development of this specific morphology. It guarantees excellent high-temperature properties of the material such as a good creep resistance and dimensional stability of the material.

The following scheme shows the stages of the powder metallurgy production of tungsten wires.

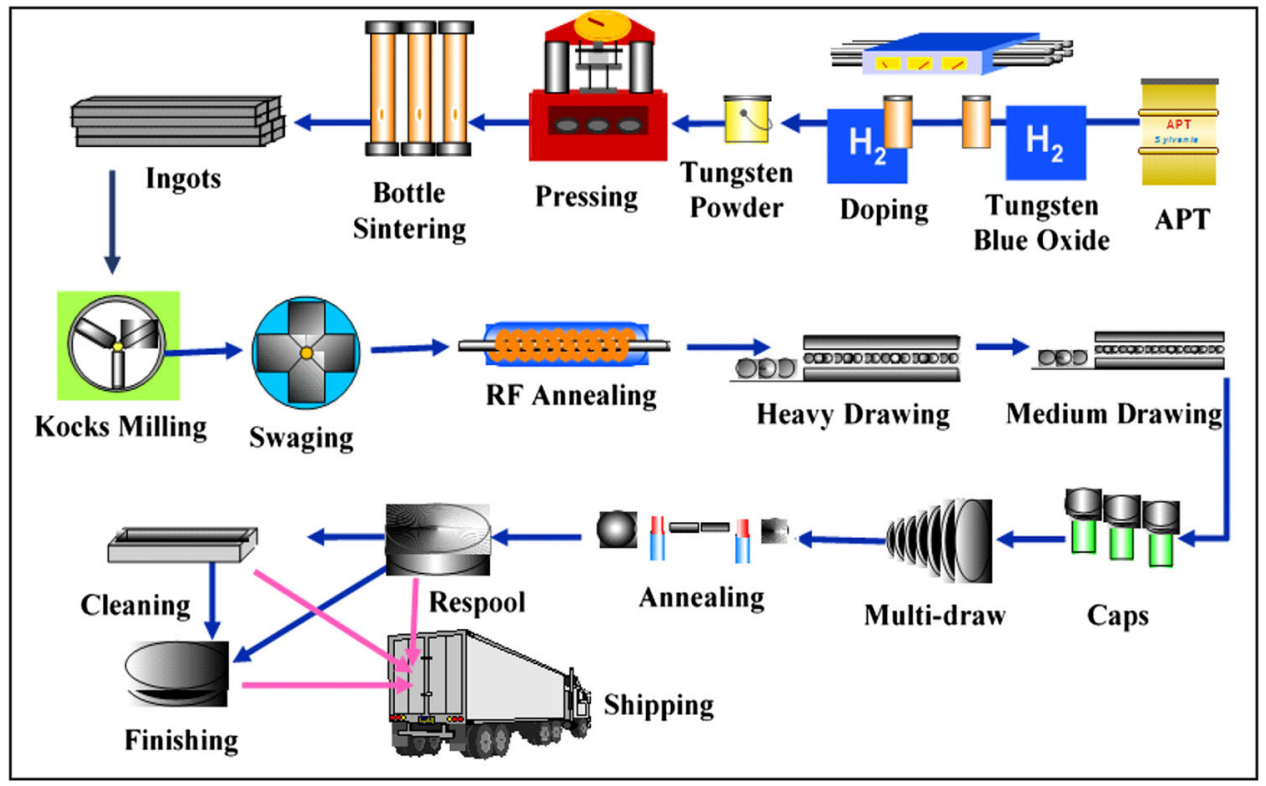

the washing treatment "survived" the whole sintering process. The large potassium atoms $(227 \mathrm{pm})$ are insoluble in the tungsten lattice. They are being stabilized by the equilibrium between the Laplace pressure (capillary or curvature pressure) of the potassium bubbles and the internal potassium vapor pressure, which is considerably high at elevated temperature.

(D) The subsequent hot deformation of the sintered ingot by rolling, swaging, and drawing processes leads to significant changes of the microstructure. At first potassium-filled long ellipsoids or tubes are formed. At medium annealing temperatures, individual bubbles and/or bubble rows are generated. As soon as the individual potassium bubbles have been formed at elevated temperature by disintegration of the ellipsoids, they grow to their equilibrium size. A standard potassium-doped tungsten wire can contain
Infrared coating of the bulb

The infrared radiation component of light can be reflected back to the filament by coating the glass bulb. Thereby, the power consumption will be reduced keeping the filament's temperature. Based on the patent-protected procedure IRC (infrared coating), a special coating is externally applied on the bulb [25]. It works like a mirror by reflecting the infrared radiation back on the filament. In connection with special bulb geometry, the coil gets an additional heating. Less electric energy must be supplied, to bring the filament to its working temperature. Under otherwise identical conditions, the durability of IR-coated lamps is more than twice as long as a standard halogen lamp. IRC lamps are used particularly in the areas of airfield and medical lighting. In case of airfield lighting, the lamps are optimized with regard to their life. In the field of medicine, IRC lamps score by their high light output. 


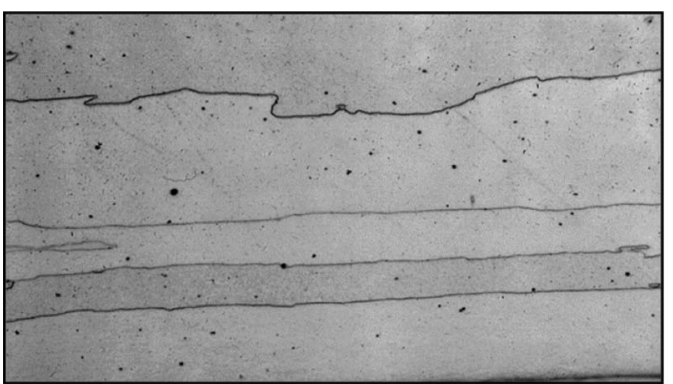

(a)

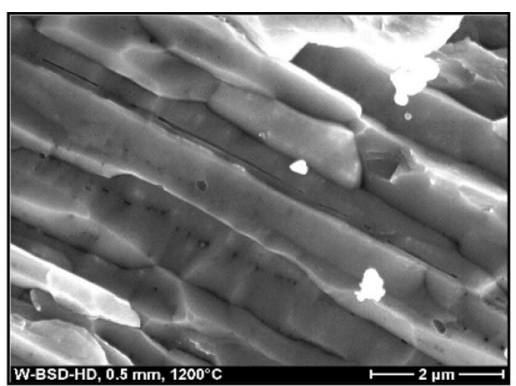

(b)

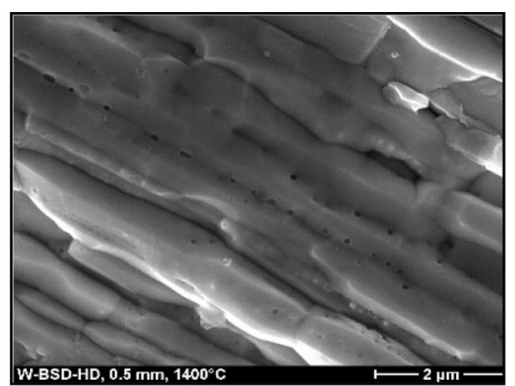

(c)

Fig. 8 Potassium-doped tungsten wire (diameter $0.5 \mathrm{~mm}$ ). a Photomicrograph. b Annealed at $1,200{ }^{\circ} \mathrm{C}$. c Annealed at $1,400{ }^{\circ} \mathrm{C}$

\section{Light parameters}

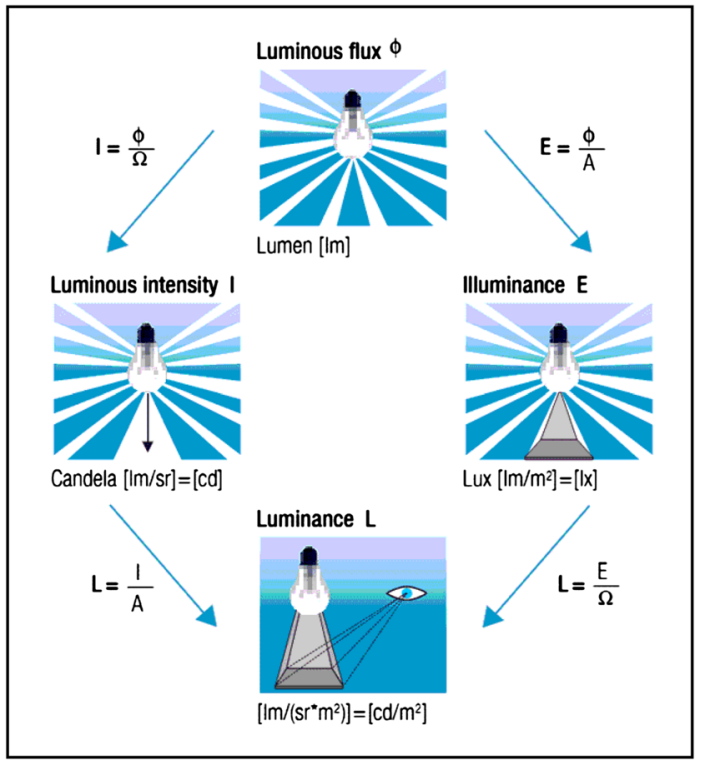

The luminous flux $\Phi$ [Unit Lumen (Im)] describes the quantity of light emitted by a light source.

The luminous efficacy [Unit $\mathbf{I m} \mathbf{W}^{-\mathbf{1}}$ ] is the ratio of the luminous flux to the electrical power consumed. It is a measure of a lamp's economic efficiency.

The luminous intensity I [Unit Candela (cd)] describes the quantity of light that is radiated in a particular direction. This is a useful measurement for directive lighting elements such as reflectors. It is represented by the luminous intensity distribution curve (LDC).

The Illuminance $E$ [Unit Lux (lx)] describes the quantity of luminous flux falling on a surface. It decreases by the square of the distance (inverse square law).

The luminance $\boldsymbol{L}$ [Unit $\left(\mathbf{c d} / \mathbf{m}^{2}\right)$ ] is the only basic lighting parameter that is perceived by the eye. It specifies the brightness of a surface and is essentially dependent on its reflectance (finish and color).
The color temperature of a light source is the temperature of an ideal black-body radiator that radiates light of comparable hue to that of the light source. Color temperatures over 5,000 K are called cool colors (bluish white), while lower color temperatures $(2,700-3,000 \mathrm{~K})$ are called warm colors (yellowish white through red).

The color rendering index (CRI) is a quantitative measure of the ability of a light source to reveal the colors of various objects authentically in comparison with a natural light source. Natural outdoor light has a CRI of 100 and is the standard of comparison for any other light source. Light sources with a high CRI are desirable in color-critical applications such as photography and cinematography.

The luminous efficacy of the various incandescent lamps is presented in Table 4 .

\section{Outlook}

Worldwide $6.5 \%$ of generated energy is consumed by lighting. "In a long run, an efficiency improvement of lighting would hardly save energy." That is at least the

Table 4 Luminous efficacy of incandescent lamps

\begin{tabular}{lll}
\hline Incandescent lamp & Year & $\begin{array}{l}\text { Luminous efficacy } \\
\left(1 \mathrm{~m} \mathrm{~W} \mathrm{~W}^{-1}\right)\end{array}$ \\
\hline Carbon filament lamp & 1880 & $1 \ldots 2$ \\
Nernst lamp & 1897 & $4 \ldots 6$ \\
Osmium lamp & 1902 & $6,5 \ldots 7$ \\
Tantalum lamp & 1905 & $6 \ldots 6,5$ \\
$\begin{array}{l}\text { Tungsten filament lamp (vacuum) } \\
\text { Tungsten filament lamp (argon- }\end{array}$ & 1911 & $6 \ldots 9$ \\
$\quad 1914$ & 12 \\
$\begin{array}{l}\text { Tungsted) } \\
\text { lamp coiled-coil filament }\end{array}$ & 1926 & 15 \\
Tungsten halogen lamp & 1959 & $20 \ldots 25$ \\
IRC lamp & 1996 & $25 \ldots 30$ \\
\hline
\end{tabular}




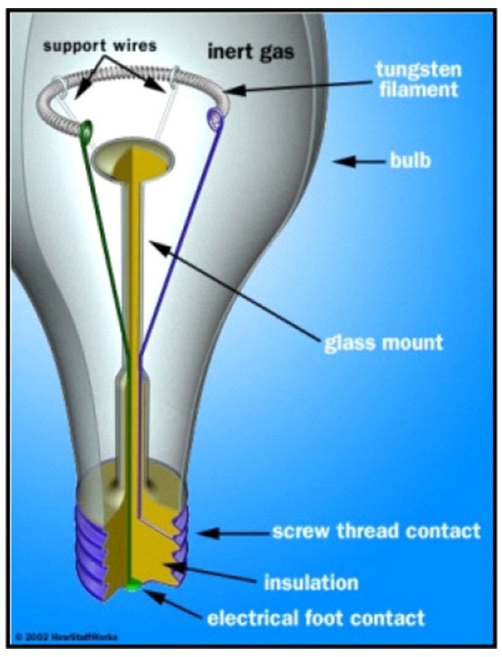

Fig. 9 Details of a modern incandescent lamp

conclusion of the experts of the Sandia National laboratories presented in their study [26]. According to their model, the energy required for generation of light would drop only when the price of electricity would triple. For the ongoing change to light-emitting diode (LED) lamps, the same researchers predict that light consumption during the next 20 years would rise by a factor of 10 combined with the doubled energy consumption. For the modeling, they took into account the global economic performance, the energy price, and the efficiency of the lamps. For LEDs, they considered a threefold enhanced efficiency compared to fluorescent lighting; for the power cost, they assumed today's level. Therefore, LED lamps would eliminate no power plants at all.

In 2007 , Germany used more than $10 \%$ of the total electricity consumption for lighting. The share of industry, trade, and services amounted to over $20 \%$, while the households used $8 \%$ and the industry $5 \%$.

Legislation in many countries including the US has mandated phasing out the incandescent bulb for more energy efficient options such as compact fluorescent and
Table 5 Light output, lifetime, and color rendering index of alternative light sources

\begin{tabular}{|c|c|c|c|}
\hline Light source & $\begin{array}{l}\text { Luminous } \\
\text { efficiency } \\
\left(1 \mathrm{~m} \mathrm{~W}^{-1}\right)\end{array}$ & Service life $(\mathrm{h})$ & CRI \\
\hline $\begin{array}{l}\text { White light- } \\
\text { emitting diode } \\
\text { (LED) }\end{array}$ & $10 \ldots 100$ & up to 100,000 & 90 \\
\hline $\begin{array}{l}\text { Energy-saving } \\
\text { lamp }\end{array}$ & $35 \ldots 75$ & $8,000 \ldots 15,000$ & $>82$ \\
\hline Fluorescent lamp & $50 \ldots 105$ & $8,000 \ldots 20,000$ & $80 \ldots 100$ \\
\hline Cold cathode tube & $40 \ldots 80$ & $30,000 \ldots 50,000$ & $>90$ \\
\hline Metal halide lamp & $60 \ldots 100$ & $9,000 \ldots 15,000$ & 90 \\
\hline $\begin{array}{l}\text { High-pressure } \\
\text { mercury lamp }\end{array}$ & $30 \ldots 60$ & 10,000 & $45 \ldots 58$ \\
\hline $\begin{array}{l}\text { High-pressure } \\
\text { sodium lamp }\end{array}$ & $70 \ldots 150$ & $20,000 \ldots 32,000$ & $25 \ldots 40$ \\
\hline $\begin{array}{l}\text { Low-pressure } \\
\text { sodium lamp }\end{array}$ & $100 \ldots 200$ & $12,000 \ldots 18,000$ & 25 \\
\hline Induction lamp & $80 \ldots 100$ & $50,000 \ldots 100,000$ & $80 \ldots 89$ \\
\hline
\end{tabular}

LED lamps. Since 2005 in many countries, production and sales of incandescent light bulbs with low light output are banned in order to save energy. The light bulb ban is also part of the EU reform "Energy 2020" and is intended to reduce the energy consumption of all $28 \mathrm{EU}$ members by $20 \%$. This reform was necessary in order to counteract climate change. To achieve this goal, energy must be saved. There exist various approaches such as renewable energy and climate-friendly cars.

Why must the classic light bulb be banned now? To answer this question, we will have a brief look at the functionality (Fig. 9) and the energy consumption of a light bulb. The incandescent lamp consists of a base, which allows the power supply. The tungsten filament is heated by the current and generates the light. Modern incandescent lamps are not energy efficient. Only less than $10 \%$ of electrical power supplied to the bulb is converted into visible light. The remaining energy is lost as heat.
Fig. 10 Customers' resentments
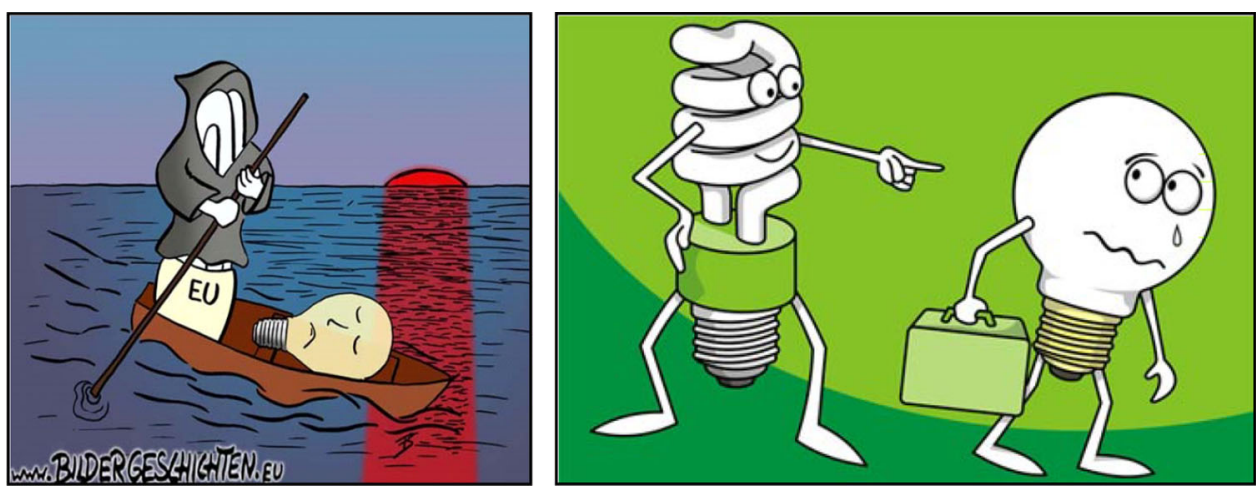
However, these inefficient light bulbs are still widely used today due to many advantages such as

- wide, low-cost availability;

- easy incorporation into electrical systems;

- adaptable for small systems;

- low voltage operation, such as in battery powered devices; and

- wide shape and size availability.

There have been much resentments of the customers to the governmental regulations owing to the low cost of incandescent lamps (Fig. 10).

The alternatives to halogen light bulbs are not necessarily what customers want. All lamp types listed in Table 5 are in fact significantly more energy-efficient than halogen bulbs. However, eight of the nine lamps need mercury for their operation, in elemental form or as amalgam. LED lamps are the only exception. Each fluorescent lamp contains about four milligrams of extremely poisonous mercury. Albeit the mercury content in a single lamp is very low, the mercury amount piles up, considering their millionfold use. Despite all efforts to recycle the mercury-containing lamps, still too many of them end up in a landfill. The released mercury will contaminate the atmosphere. Moreover, the LED lamps are very expensive and not always grant the promised long service life. The light quality of all modern types of lamps is undoubtedly worse than that of the tungsten incandescent lamp. Most LED lights do not have a CRI above 90.

\section{References}

1. Bolton Wv (1906) Angew Chem 19:1537-1540

2. Agte C, Vacek J (1959) Wolfram und Molybdän. AkademieVerlag, Berlin

3. Rieck GD (1967) Tungsten and its compounds. Pergamon Press, Oxford
4. Zelikman AN, Nikitina LS (1978) Vol'fram (in Russian). Metallurgija, Moskva

5. Pink E, Bartha L (1989) The metallurgy of doped non-sag tungsten. Elsevier, London

6. Lassner E, Schubert WD (1999) Tungsten: properties, chemistry, technology of the element, alloys, and chemical compounds. Kluwer Academic/Plenum Publishers, New York

7. Lassner E, Schubert WD (2009) Tungsten: the past, the present, the future. Brochure of ITIA (Intenational Tungsten Industry Association), London

8. Sobolevsky PG (1827) Gornyj Zhurnal (Russia) 2:84

9. Sobolevsky PG reproduced (1927) in Ann Inst Platine (Leningrad) 5:206-219

10. Huheey JE, Keiter EA, Keiter RL (2014) Anorganische Chemie-Prinzipien von Struktur und Reaktivität. Walter de Gruyter GmbH, Berlin/Boston, pp 967-984

11. Lunk HJ, Ziemer B, Salmen M, Heidemann D (1993-1994) Refract Metals Hard Mater 12:17-26

12. Tilley R (2000) Colour and the optical properties of materials. Wiley \& Sons, Chichester

13. Zubler EG, Mosby FA (1959) Illum Engn 54:734-740

14. Pacz A (1922) Metal and its manufacture, US Patent $1,410,499$

15. Spier HL (1962) Influence of chemical additions on the reduction of tungsten oxides. Thesis, Technological University Eindhoven

16. Moon DM, Sticker R, Wolfe AL (1968) 6th International Plansee Seminar. In: Benesovsky F (ed) Proceedings 1968, SpringerVerlag, Wien, pp 67-85

17. Snow DB (1974) Metallurg Trans 5:2375-2381

18. Bewlay P, Briant CL (1995) Int J Refract Met Hard Mat 13:137-159

19. Gaal I, Schade P, Harmat P, Horacsek O, Bartha L (2006) Int J Refract Met Hard Mat 24:311-320

20. Schade P (2010) Int J Refract Met Hard Mat 28:648-660

21. Lunk HJ (1982) Neue Hütte 27:329-334

22. Lunk HJ, Hübener S (1989) 12th International plansee seminar. In: Bildstein $\mathrm{H}$, Ortner $\mathrm{H}$ (eds) Proceedings vol. 1, RM 11, pp 133-150

23. Ziemer B, Lunk HJ (1989) 12th International plansee seminar. In: Bildstein $\mathrm{H}$, Ortner $\mathrm{H}$ (eds) Proceedings Vol. 1, RM 45, pp 471-481

24. Lunk HJ, Schade P (1982) Neue Hütte 27:382-387

25. Bunk A, Klam R, Ender E, Gloeckler F (1996) US 5,548,182

26. Tsao JY, Saunders HD, Creighton JR, Coltrin ME, Simmons JA (2010) J Phys D Appl Phys 43:354001 